\title{
Thinking and Working Politically on transboundary issues
}

Izzy Birch

Independent researcher

18 January 2021

\section{Question}

What are the key challenges to Thinking and Working Politically (TWP) when designing and delivering development interventions around transboundary issues? How have tools and concepts, including Political Economy Analysis, been adapted to overcome these challenges and what lessons have been learned?

\section{Contents}

1. Summary

2. Thinking and Working Politically

3. Challenges of TWP on transboundary issues

4. Tools and concepts adapted for transboundary settings

5. Lessons learned

6. References

The K4D helpdesk service provides brief summaries of current research, evidence, and lessons learned. Helpdesk reports are not rigorous or systematic reviews; they are intended to provide an introduction to the most important evidence related to a research question. They draw on a rapid deskbased review of published literature and consultation with subject specialists.

Helpdesk reports are commissioned by the UK Foreign, Commonwealth, and Development Office and other Government departments, but the views and opinions expressed do not necessarily reflect those of FCDO, the UK Government, K4D or any other contributing organisation. For further information, please contact helpdesk@k4d.info. 


\section{Summary}

There is growing consensus that political factors are a key determinant of development impact. The practice of Thinking and Working Politically (TWP) is built around three inter-connected principles: (i) strong political analysis, insight and understanding; (ii) detailed appreciation of, and response to, the local context; and (iii) flexibility and adaptability in program design and implementation. From the limited experience thus far of applying TWP on transboundary issues, the following challenges are apparent:

1. The process becomes more complex as both the number of actors and the diversity of interests and incentives increase.

2. There are variations in the political traction attached to different policy areas and the institutions responsible for them.

3. Geo-political sensitivities shape the space for transboundary cooperation, which is therefore vulnerable to opening and closing unpredictably.

4. There are differing interpretations of what is 'regional'. Further, transboundary interventions are not always a response to a failure of collective action at that level.

5. The governance of transboundary issues is likely to involve the interplay of multiple institutions operating at different levels. Practitioners must then navigate this complexity.

Some of the lessons learned are as follows:

1. While TWP emphasises the centrality of politics and power, technical knowledge is still important and can reinforce the political agenda, for example by increasing the confidence of smaller states or by strengthening collective understanding.

2. Improving the quality of domestic cooperation can be a step towards regional cooperation.

3. Flexible engagement with the diverse range of actors that populate transboundary settings has been shown to be an effective strategy.

4. Transboundary cooperation can be built from the bottom up, either by focusing spatially or by working incrementally in modest steps.

5. For development partners, pre-existing bilateral partnerships may facilitate their engagement at a transboundary level, particularly on sensitive issues.

Given the relatively isolated experience of TWP in transboundary settings, the evidence base for this report is also limited. The two areas where most examples were found concern regional integration and transboundary water management.

While there has been some work to advance TWP and gender, neither gender nor disability were features of the literature under review. 


\section{Thinking and Working Politically}

There is growing consensus that the critical success factor in achieving developmental change is a deep understanding of, and active engagement with, local political and power relations (Laws \& Marquette, 2018). ${ }^{1}$ The practice of Thinking and Working Politically (TWP) reflects this consensus and is guided by three core principles (Table 1 ).

See: Table 1: Thinking and Working Politically: Principles and Characteristics, Source: TWP Community of Practice (nd), p. 2, https://wpcommunity.org/wp-content/uploads/2018/02/thecase-for-thinking-and-working-politically.pdf

Political economy analysis (PEA) underpins TWP by exploring the distribution and contestation of political and economic power and the implications of this for development (McGregor et al, 2020). PEA may be applied in different ways and at different levels of operation (Harris \& Booth, 2013). Practitioners with the right skill-set can incorporate the insights from PEA into their ongoing work, thus connecting the two complementary elements ('thinking' and 'working') of TWP (McGregor et al, 2020).

A recent evidence review of TWP (Dasandi et al, 2019; Laws \& Marquette, 2018) finds that its literature has certain limitations, including in rigour and robustness, and in its capacity to demonstrate that TWP can deliver better development outcomes; the authors also note the lack of journal articles. The same evidence review indicates that most of the contexts in which TWP has been applied are country-based, even if programmes are designed or managed regionally. In 2017, the TWP Community of Practice discussed how TWP might extend its scope to address 'larger and messier' development challenges that cross national boundaries (TWP Community of Practice, 2017, p. 2). The two case studies presented at that meeting were on transboundary water management and regional integration, and these two issues provide most of the material in this report. The searches for this report, reinforced by consultation with members of the TWP Community of Practice, suggest that the application of TWP in transboundary settings is still limited.

\section{Challenges of TWP on transboundary issues}

1. The larger number of actors, each with their differing interests and incentives, makes the process of TWP more complex. Transboundary analysis is multi-layered: it needs to explore the political dynamics within each country, as well as those between countries, and the interaction between the two (Byiers \& Vanheukelom, 2016). Transboundary dynamics also play out within countries, particularly over shared natural resources (Tincani et al, 2018). The multi-dimensional nature of transboundary issues brings in a wide range of actors and presents challenges for PEA, which risks being

\footnotetext{
${ }^{1}$ In their discussion of TWP and biodiversity, Schuttenberg et al (2020) note that 'local', when used in the context of TWP, does not imply working at a small geographical scale but rather distinguishes between local actors and outsiders. It does not rule out working on the larger scale that an ecosystem approach may require.
} 
overly general or unfocused unless the research question is tailored to the specific needs of the team at that time (World Bank, 2017).

2. The political traction attached to different policy areas varies. In their synthesis of the findings from the Political Economy Dynamics of Regional Organisations (PEDRO) programme, Byiers et al (2019) show that different cross-border issues, such as trade, security, energy, or ecosystem management, have different political imperatives that alter the incentives to engage across borders. For example, immediate threats carry greater political urgency than aspirational agendas focused on the creation of future benefits. Those sectors where country priorities are largely national or local in nature, such as water in Southern Africa, are unlikely to generate strong incentives for regional cooperation (Woolfrey \& Muller, 2017). ${ }^{2}$ The power of sector ministries also varies: WellsDang et al (2016), reviewing the political economy of environmental impact assessments in the Mekong region, note the limited influence and authority of environment ministries, and the risk that generous donor support may isolate them still further from the more influential parts of government.

3. The space for transboundary cooperation is politically sensitive, shaped by geopolitical priorities, and can open and close unpredictably. 'Resource nationalism', in which cross-border cooperation over natural resources is determined by wider geo-political considerations, is a particular challenge; Stanbury-Davis (2018) discusses how governments in Asia regard rivers as both national assets and tools for managing their external affairs. Unrelated political events can stall progress on collective action (Tincani et al, 2018).

4. There are differing interpretations of what is 'regional', or transboundary. Regions exist on a variety of spatial scales and levels which may be understood differently by different actors, and which may overlap with each other or function in parallel. The range of a regional or transboundary issue and the mechanism intended to manage it may not coincide; an eco-region and a political region, for example, may in practice occupy separate geographical spaces (Söderbaum \& Granit, 2014). ${ }^{3}$

Further, the added value of transboundary action is not always apparent; nor does it necessarily drive regional cooperation. Byiers et al (2019) find that not all activities carried out by regional organisations are responses to a failure of collective action at the regional level; many appear to be projects that happen to be implemented by a regional organisation in more than one country.

5. The governance of transboundary issues is likely to involve the complex interplay of multiple institutions operating at different levels. This may be a consequence of asymmetries in governance at the national level. For example, since water governance in India is a state-level function, transboundary discussions are influenced by the political dynamics within India's basin states, which are themselves also key actors in those

\footnotetext{
2 Woolfrey \& Muller (2017) also attribute the lack of regional traction to a divergence between the priorities of national governments and development partners. The water priorities of member states of the Southern African Development Community (SADC) are largely driven by their national development concerns, such as energy generation and economic development, rather than the conservation and environmental agenda favoured by development partners.
}

\footnotetext{
${ }^{3}$ The authors list six types of region: (i) eco-region, (ii) cultural region, (iii) economic region, (iv) administrative region, (v) political region, and (vi) security region.
} 
interactions, thus complicating the process of international negotiation (Stanbury-Davis, 2018).

There may be multiple overlapping frameworks of decision-making and cooperation with responsibility for the same resource. These are two examples:

i. Jensen \& Lange (2013) categorise the various forms of water governance in the Mekong and Zambezi river basins: (i) unilateral water development interventions by a single country that affect the basin; (ii) bilateral cooperation agreements governing specific projects in the basin; (iii) bilateral water agreements between riparian countries and basin water commissions; (iv) multilateral water agreements between three or more countries; and ( $v$ ) regional cooperative frameworks, such as the Association of Southeast Asian Nations (ASEAN) or the Southern African Development Community (SADC).

ii. Knaepen \& Byiers (2017) explore the institutional arrangements in the Nile Basin. The Nile Basin Initiative (NBI) is an intergovernmental partnership of ten Nile Basin countries to promote collaboration and benefit-sharing. Most are also members of the Intergovernmental Authority on Development, which is also developing a regional water strategy. Other actors involved in managing Nile waters include the Lake Victoria Basin Commission under the East African Community (EAC), and the East Africa Power Pool under the Community of East and Southern Africa.

It should also be noted that authority is exercised, and regional cooperation may be pursued, through informal as well as formal mechanisms such as those listed above, and by private as well as public actors, further adding to the institutional complexity (Byiers et al, 2019; Söderbaum \& Granit, 2014).

\section{Tools and concepts adapted for transboundary settings}

Given the limited body of literature on transboundary TWP, it was not possible to identify a wide number of tools and concepts adapted to this context. However, two are summarised here: the first from the literature on regional integration and the second from the literature on transboundary water management.

\section{Five-lens tool}

The PEDRO research programme sampled and adapted PEA frameworks and tools commonly used at country and sector level to inform the development of a 'five lens' framework for analysing the political economy of regional cooperation (Byiers \& Vanheukelom, 2016). The five lenses interact with each other and are as follows:

1. Structural or foundational factors

2. Formal and informal institutions / rules of the game

3. Actors, agency and incentives

4. (Sub)-sector-specific technical and political characteristics

5. External or exogenous factors. 
The authors note that this approach is broadly in line with the TWP agenda, in that political analysis and contextual understanding should inform programming that is flexible and adaptable in design. To that end, Byiers \& Vanheukelom (2016) present five options that can guide decisions about a programme's level of ambition, which reflect what is politically feasible and will work 'with the grain', rather than from a normative template. The five options, with their key guiding questions, are:

1. Alter: Given the context laid out using the five lenses, what are the chances of being able to alter the interests of key stakeholder groups and actors?

2. Adapt: To what degree can objectives be met, or can 'the problem' be addressed building on existing incentives and informal practices?

3. Avoid: What are the prospects, but also the potential costs and benefits of working through alternative and/or parallel processes and institutional forms?

4. Await: Are there some potentially important political or other game changers on the horizon that might offer better opportunities for reform?

5. Abandon: Assuming none of the other 4 A's apply, is abandoning the intervention or reform politically feasible or desirable, and might any negative effects otherwise be offset?

\section{Perceived risks to cooperation}

The Cooperation in International Waters in Africa (CIWA) initiative has published guidance on PEA for transboundary water management (World Bank, 2017). This takes a problem-driven approach to PEA, the five steps in the analysis being (i) problem definition, (ii) context, (iii) institutional arrangements, (iv) underlying drivers, and (v) 'what can be done?'

In exploring steps 3 and 4 (institutions and drivers) the guidance recommends a tool that analyses countries' perceived risks to cooperation and helps draw out underlying concerns and priorities. The risks are clustered in five areas and defined as follows (World Bank, 2017, p. 9):

1. Capacity and knowledge: Confidence in the ability to negotiate a fair deal; having adequate and correct information and knowledge to negotiate a deal.

2. Accountability and voice: Deliverability of benefits by the regional entity and coriparians, often related to trust; having a say in decision making in the governing structures of the regional entity.

3. Sovereignty and autonomy: Ability to act in the best interest of the country without constraints; making decisions independently.

4. Equity and access: Fairness of (relative) benefits to a country, including timing of benefits and costs and obtaining/retaining fair access to the river.

5. Stability and support: Potential longevity of the agreement; in-country support of the agreement, including likelihood of ratification.

\section{Other frameworks}

The searches for this report identified a number of other frameworks and analytical lenses which, while they may not be explicitly associated with TWP, nevertheless recognise the centrality of politics and power, the limitations of technocratic approaches, and the need to adapt to 
complexity and uncertainty. There was insufficient time to explore these in any depth given the size of the literature, but two may be relevant:

1. Water Diplomacy Framework: this is presented as an alternative to technically focused water management approaches (Islam \& Repella, 2015). It starts by exploring the values and interests of stakeholders, acknowledging the need to incorporate diverse viewpoints. It then seeks 'politically legitimate and tentative prescriptions' given the high levels of both complexity and uncertainty. The authors comment: 'Our challenge is how to translate solutions that emerge from science and technology into the messy context of the economy and politics' (Islam \& Repella, 2015, p. 1).

2. Political ecology analysis: this is an interdisciplinary approach to understanding environmental processes that incorporates some aspects of political economy. Nash (2020) argues that it can reinforce efforts to think and work politically in the area of conservation and natural resource management, for example by understanding how uneven power relations influence corruption.

\section{Lessons learned}

1. While TWP emphasises the centrality of politics and power, technical knowledge is still important and can reinforce the political agenda. For example:

a. Strengthening technical competence can help to level the transboundary playing field. An evaluation of the South Asia Water Initiative found that smaller countries in the region felt more confident negotiating with their larger and more powerful neighbours once they had a clearer technical understanding of the issues (Tincani et al, 2018).

b. Technical collaboration and trust-building can build shared understanding of the regional challenges faced. The Nile Basin Initiative (NBI) enhanced its legitimacy with member states by positioning itself as a knowledge broker, developing an analytical and modelling tool that facilitates shared understanding of river behaviour and the likely impact of different intervention scenarios (Medinilla, 2018). The NBI works in an adaptive manner in a complex political environment, using its technical services to strengthen political relations (Knaepen \& Byiers, 2017). Empowering a regional institution to provide technical knowledge services may in some cases be less politically sensitive than starting from more ambitious regional agendas (Medinilla, 2018).

2. Improving the quality of domestic cooperation can be a step towards regional cooperation. The South Asia Water Initiative evaluation found that reducing the communication gaps between national ministries (such as those responsible for finance, external affairs, energy, and water) was an important first step towards achieving the cohesive approach necessary for regional cooperation to work (Tincani et al, 2018).

3. Flexible engagement with a diverse range of actors is an effective strategy. Many different actors may be trying to influence decision-making on transboundary issues, such as civil society organisations, the private sector, the media, and researchers, as well as various public bodies. In such a crowded space, experience from the Mekong region suggests that the organisations and networks which are particularly effective in 
facilitating dialogue on politically sensitive issues are those that have invested in their relationships with many of these different players (TWP Community of Practice, 2017).

4. Transboundary cooperation can be built from the bottom up. Sub-regional cooperation may be more politically feasible, since the smaller number of countries involved increases the chance that their interests may align. There are several examples of this:

a. The corridor approach to trade and industrialisation adopted by some regional bodies such as SADC and the EAC (Byiers et al, 2019).

b. A spatial approach based around specific natural resources, such as the different sub-groups and investment programmes associated with different parts of the Nile waters (Medinilla, 2018).

c. The Transfrontier Conservation Areas in Southern Africa, where strong cross-border collaboration at the local level is identified as being key to their successful implementation. Moreover, the political stakes were kept relatively low (Bertelsmann-Scott, 2013). The process of developing these areas proceeded in small steps which did not significantly challenge national sovereignty (Vanheukelom \& Bertelsmann-Scott, 2016).

5. Transboundary cooperation can also be politically sensitive and take time. In these circumstances, building the necessary trust is a slow process that is vulnerable to being reversed. It is therefore important to identify what each programme has achieved, as well as what remains to be done, so that the wider sector can sustain momentum over the longer term (Tincani et al, 2018).

6. For development partners, pre-existing bilateral partnerships may facilitate their engagement at a transboundary level. An evaluation of the approach to policy dialogue used in the Greater Mekong Water Resources Program by Australia's Department of Foreign Affairs and Trade (DFAT) noted that DFAT's involvement in difficult transboundary issues was made relatively easier by it being already recognised as a partner in each country (Pech \& Mather, 2017).

\section{References}

Bertelsmann-Scott, T. (2013). The impact of Transfrontier Conservation Areas on regional integration. PERISA Case Study 3 on Public Goods. South African Institute of International Affairs / European Centre for Development Policy Management.

https://ecdpm.org/publications/impact-transfrontier-conservation-areas-regional-integration/

Byiers, B., Woolfrey, S., Medinilla, A. \& Vanheukelom, J. (2019). The political economy of Africa's regional 'spaghetti bowl'. Political Economy Dynamics of Regional Organisations in Africa (PEDRO), Synthesis Report. European Centre for Development Policy Management. https://ecdpm.org/publications/political-economy-africas-regional-spaghetti-bowl-synthesis-report/

Byiers, B. \& Vanheukelom, J. (2016). A 'how to' note - doing regional development differently. A political economy analysis framework for identifying drivers and constraints to regional integration. European Centre for Development Policy Management.

https://ecdpm.org/publications/doing-regional-development-differently/ 
Dasandi, N., Laws, E., Marquette, H. \& Robinson, M. (2019). What does the evidence tell us about 'Thinking and Working Politically' in development assistance? Politics and Governance, 7:2, 155-168. DOI: 10.17645/pag.v7i2.1904

Harris, D. \& Booth, D. (2013). Applied political economy analysis: five practical issues. Overseas Development Institute. https://www.odi.org/publications/7196-applied-political-economy-analysis-fivepractical-issues

Islam, S. \& Repella, A. C. (2015). Water diplomacy: A negotiated approach to manage complex water problems. Journal of Contemporary Water Research and Education, 155: 1-10. https://doi.org/10.1111/j.1936-704X.2015.03190.x

Jensen, K. M. \& Lange, R. B. (2013). Transboundary water governance in a shifting development context: New development finance, development spaces and commitment to cooperation: $A$ comparative study of the Mekong and the Zambezi river basins. Danish Institute for International Studies (DIIS) Report 2013:20. https://www.diis.dk/en/research/transboundary-water-governance-ina-shifting-development-context-0

Knaepen, H. \& Byiers, B. (2017). The Nile Basin Initiative: Balancing historical rights, national needs and regional interests. PEDRO Policy Brief. European Centre for Development Policy Management. https://ecdpm.org/publications/nile-basin-initiative-balancing-historical-rights-nationalneeds-regional-interests/

Laws, E. \& Marquette, H. (2018). Thinking and working politically: Reviewing the evidence on the integration of politics into development practice over the past decade. TWP Community of Practice. https://twpcommunity.org/wp-content/uploads/2018/04/Thinking-and-working-politicallyreviewing-the-evidence.pdf

McGregor, L., Frazer, S., \& Brinkerhoff, D. W. (2020). Thinking and working politically: Lessons from diverse and inclusive applied political economy analysis. RTI Press Publication No. RR0038-2004. Research Triangle Park, NC: RTI Press.

https://doi.org/10.3768/rtipress.2020.rr.0038.2004

Medinilla, A. (2018). African river basin organisations: From best practice to best fit. Political Economy Dynamics of Regional Organisations in Africa (PEDRO), Discussion Report No. 236. European Centre for Development Policy Management. https://ecdpm.org/publications/africanriver-basin-organisations-from-best-practice-to-best-fit/

Nash, R. (2020). A political ecology lens for addressing corruption in conservation and natural resource management. Targeting Natural Resource Corruption.

https://www.worldwildlife.org/pages/tnrc-introductory-overview-a-political-ecology-lens-for-addressingcorruption-in-conservation-and-natural-resource-management

Pech, S. \& Mather, R. (2017). Evaluative study: DFAT Greater Mekong Water Resources Program's approach to policy dialogue. Department of Foreign Affairs and Trade.

https://www.dfat.gov.au/sites/default/files/greater-mekong-water-resource-program-approach-policydialogue-evaluative-study.pdf 
Schuttenberg, H. Z., Stark, J. \& Schueler, K. (2020). Technically strong and politically savvy: Enhancing Thinking and Working Politically when practicing the Conservation Standards at USAID. USAID: Washington, D.C. https://rmportal.net/biodiversityconservationgateway/projects/current-global-projects/bridge/bridge-resources/supplemental-guide-4-technicallystrong-and-politically-savvy-enhancing-thinking-and-working-politically-when-practicing-theconservation-standards-at-usaid/view

Söderbaum, F. \& Granit, J. (2014). The political economy of regionalism: The relevance for transboundary waters and the Global Environment Facility. In Ulf Johansson Dahre (Ed.) Resources, peace and conflict in the Horn of Africa: A report on the 12th Horn of Africa Conference, Lund, Sweden, August 23-25, 2013, p. 109. Lund University.

https://www.academia.edu/10090582/Resources_Peace_and_Conflict_in_the_Horn_of_Africa

Stanbury-Davis, P. (2018). Political economy analysis of Asia's transboundary rivers. Department for International Development. https://img1.wsimg.com/blobby/go/57f3b7f1-aa75-4981-b8dfc08b3372cb2e/downloads/The\%20political\%20economy\%20of\%20the\%20international\%20riv.pdf?ver=1 569928577171

Tincani, L., Sinha, R., Buchy, M. \& Singh, P. (2018). Evaluation of the South Asia Water Initiative Phase II (SAWI-II). Oxford Policy Management.

TWP Community of Practice. (2017). Big messy problems: Workshop report. London, 7 June 2017. https://twpcommunity.org/wp-content/uploads/2017/09/London-meeting-report.pdf

TWP Community of Practice. (nd). The case for thinking and working politically: The implications of 'doing development differently'. https://twpcommunity.org/wp-content/uploads/2018/02/the-casefor-thinking-and-working-politically.pdf

Vanheukelom, J. \& Bertelsmann-Scott, T. (2016). The political economy of regional integration in Africa: The Southern African Development Community (SADC) Report. European Centre for Development Policy Management. https://ecdpm.org/publications/political-economy-regionalintegration-africa-sadc/

Wells-Dang, A., Nyi Soe, K., Inthakoun, L., Tola, P., Socheat, P., Van Nguyen, T. T., Chabada, A. \& Youttananukorn, W. (2016). A political economy of environmental impact assessment in the Mekong Region. Water Alternatives, 9 (1): 33-55.

https://www.cabdirect.org/cabdirect/abstract/20163123124

Woolfrey, S. \& Muller, M. (2017). The SADC Water Agenda: Managing or developing regional water resources? PEDRO Policy Brief. European Centre for Development Policy Management. https://ecdpm.org/publications/sadc-water-agenda-managing-developing-regional-water-resources/

World Bank. (2017). Political economy analysis for transboundary water resources management in Africa: Practical Guidance. World Bank, Washington, DC.

https://openknowledge.worldbank.org/handle/10986/25824 


\section{Acknowledgements}

We thank the following experts who voluntarily provided suggestions for relevant literature or other advice to the author to support the preparation of this report. The content of the report does not necessarily reflect the opinions of any of the experts consulted.

- David Booth, Overseas Development Institute

- Bruce Byiers, European Centre for Development Policy Management

- Duncan Green, London School of Economics

- Ed Laws, Overseas Development Institute

- Neil McCulloch, The Policy Practice

- Graham Teskey, Abt Associates

\section{Key websites}

- Thinking and Working Politically Community of Practice: https:/twpcommunity.org/

- European Centre for Development Policy Management: https://ecdpm.org/dossiers/political-institutional-dynamics-regional-organisations-africa/

\section{Suggested citation}

Birch, A. (2021). Thinking and Working Politically on transboundary issues. K4D Helpdesk Report 949. Brighton, UK: Institute of Development Studies. DOI: 10.19088/K4D.2021.010

\section{About this report}

This report is based on six days of desk-based research. The K4D research helpdesk provides rapid syntheses of a selection of recent relevant literature and international expert thinking in response to specific questions relating to international development. For any enquiries, contact helpdesk@k4d.info.

K4D services are provided by a consortium of leading organisations working in international development, led by the Institute of Development Studies (IDS), with Education Development Trust, Itad, University of Leeds Nuffield Centre for International Health and Development, Liverpool School of Tropical Medicine (LSTM), University of Birmingham International Development Department (IDD) and the University of Manchester Humanitarian and Conflict Response Institute (HCRI).

This report was prepared for the UK Government's Foreign, Commonwealth and Development Office (FCDO) and its partners in support of pro-poor programmes. Except where otherwise stated, it is licensed for non-commercial purposes under the terms of the Open Government Licence v3.0. K4D cannot be held responsible for errors, omissions or any consequences arising from the use of information contained in this report. Any views and opinions expressed do not necessarily reflect those of FCDO, K4D or any other contributing organisation.

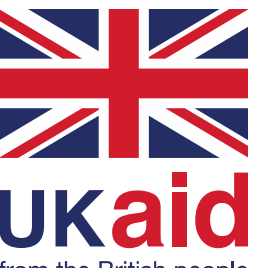

(c) Crown copyright 2021. 